\title{
DIAGNOSI DELL'INFEZIONE DA CITOMEGALOVIRUS UMANO (HCMV) IN TRAPIANTATI RENALI
}

\author{
Bergallo M., Merlino C., Costa C., Mantovani S., Sidoti F., \\ Baro S., Negro Ponzi A., Cavallo R.
}

\section{Dip. di Sanità Pubblica e Microbiologia, SCDU Virologia, Università di Torino}

L'infezione da HCMV nel trapianto d'organo rappresenta un grave problema. E' stata descritta un'ampia varietà di manifestazioni cliniche conseguenti all'infezione, ed inoltre l'HCMV può infettare l'organo trapiantato e causare disfunzione d'organo. L'inizio della terapia antivirale specifica è di solito basato sulla sintomatologia clinica e sulla rapidità della diagnosi di laboratorio. Attualmente, oltre all'isolamento rapido in shell vial (viremia), il metodo più comunemente impiegato per dimostrare l'infezione attiva da HCMV è la dimostrazione diretta di antigeni virali specifici nei leucociti circolanti, nelle biopsie o nelle cellule da lavaggio broncoalveolare. In particolare, la antigenemia-pp65 da granulociti polimorfonucleati (PMNL) è un test quantitativo rapido e accurato. Nel presente lavoro, abbiamo studiato l'infezione da HCMV in 41 pazienti portatori di trapianto renale $[28$ maschi e 13 femmine; età media 52 anni $(+/-10,8)$; tempo medio dal trapianto 90 giorni (range 20-120 giorni)].) quantificando la carica dell'HCMV-DNA nel sangue periferico mediante PCR quantitativa-competitiva (QC-PCR) messa a punto nel nostro laboratorio, correlandola con l'antigenemia-pp65, la viremia, ed un'altra tecnica molecolare, rappresentata dalla ricerca diretta degli m-RNA tardivi virali nel sangue periferico mediante Nucleic Acid SequenceBased Amplification (NASBA) che dimostra l'attività trascrizionale del virus e quindi l'infezione attiva. Come atteso, è risultato che a valori di antigenemia-pp65 più elevati $(>10$ cellule positive $/ 2 \times 10^{5} \mathrm{PMNL}$ ) e alla positività per $\mathrm{i}$ trascritti tardivi pp67 rilevati mediante NASBA, sono significativamente correlati valori elevati di HCMV-DNA (carica media: $3,77 \times 10^{6}$ genomi $/ \mathrm{ml}, \mathrm{p}=0,021$; e $8,61 \times 10^{5}$ genomi $/ \mathrm{ml}$, rispettivamente, $\mathrm{p}=0,005$ ). Non è stata invece rilevata correlazione statisticamente significativa $(\mathrm{p}=0,177$, n.s. $)$ tra il $\mathrm{n}^{\circ}$ di genomi e la positività alla viremia, ma ciò può essere spiegato dal minor riscontro di risultati positivi per la viremia $(8 / 41)$, sia a causa della difficoltà nel dimostrare l'infettività virale, sia per il fatto che i soggetti con antigenemia positiva vengono subito trattati con ganciclovir che inibisce la replicazione virale. 